\title{
A Blockchain Token-Based Trading Model for Secondary Spectrum Markets in Future Generation Mobile Networks
}

\author{
Mubbashar A. Khan $\mathbb{D}^{1},{ }^{1}$ Mohsin M. Jamali $\mathbb{D}^{2},{ }^{2}$ Taras Maksymyuk $\mathbb{D}^{3}{ }^{3}$ and Juraj Gazda $\mathbb{D}^{4}$ \\ ${ }^{1}$ Electrical and Computer Engineering Department at North Carolina Agricultural and Technical State University, \\ Greensboro NC 27401, USA \\ ${ }^{2}$ College of Engineering at the University of Texas of the Permian Basin, Texas, USA \\ ${ }^{3}$ Department of Telecommunications, Lviv Polytechnic National University, Ukraine \\ ${ }^{4}$ Department of Computers and Informatics, Technical University of Košice, 042 00, Slovakia \\ Correspondence should be addressed to Juraj Gazda; juraj.gazda@tuke.sk
}

Received 2 January 2020; Revised 8 June 2020; Accepted 11 July 2020; Published 8 August 2020

Academic Editor: Miguel López-Benítez

Copyright (C) 2020 Mubbashar A. Khan et al. This is an open access article distributed under the Creative Commons Attribution License, which permits unrestricted use, distribution, and reproduction in any medium, provided the original work is properly cited.

\begin{abstract}
Cognitive radio (CR) technology offers the possibility of an increase in spectrum utilization efficiency to resolve the prevalent spectrum scarcity problem. The economic survival of secondary spectrum markets (SSMs) is heavily dependent on the sharing of both the licensed spectrum and spectrum infrastructure by primary licensed operators (PLOs). In this research, an automated pricing model using a blockchain token called the spectrum dollar has been implemented for secondary radio spectrum trade. The use of spectrum dollars enables noncash-based secondary spectrum trade among PLOs based on a floor-and-trade rule. The pricing of spectrum dollars and the associated revenue shares are based on the underlying secondary spectrum trading behaviours of PLOs. PLOs that do not contribute enough secondary spectra to the SSM (to satisfy demand) suffer a loss proportional to the difference between their earned revenues and the specified floor value in the SSM. The secondary spectrum trade is assumed to be centrally managed by a spectrum broker, which announces the floor value for each bidding period while ensuring nonnegative revenue for the market itself. The use of the spectrum dollar along with the floor-and-trade methodology eliminates the possibilities for economic malpractice by PLOs that could increase spectrum reuse costs. In addition, the floor value provides automatic regulatory control to ensure the economic viability and prevent the technological hijacking of future SSMs.
\end{abstract}

\section{Introduction}

Currently, the utilization efficiency of numerous radio spectrum bands licensed by the Federal Communications Commission (FCC) is very low in general, while the use by existing wireless networks of specific licensed and unlicensed bands is highly congested [1-7]. One of the potential candidates to deal with this inequality is cognitive radio (CR) technology, which allows for dynamic spectrum access (DSA) [8]. DSA involves a reallocation of the underutilized portions in already-licensed radio spectrum bands to accommodate new secondary users (SUs) in an opportunistic manner [9]. The SUs coexist with the primary users (PUs) in the licensed radio spectrum on a noninterfering basis. Future secondary spectrum markets (SSMs) are heavily dependent on the licensed spectrum and communication infrastructure sharing by mutually competitive primary licensed operators (PLOs) [10]. SSMs are expected to provide a much cheaper alternative service to wireless users, because they do not require the purchase of licensed bands for their operation. If SSMs can offer a quality of service (QoS) that is comparable to that offered by PLOs, they may prove to be disruptive to the businesses of PLOs $[2,11]$. PLOs might respond to this potential existential threat and indulge in economic malpractices to manipulate certain economic parameters and impede resource sharing through SSMs. Such malpractices may raise the cost of secondary use of the radio spectrum to the extent that it is no more affordable for end-users than use of the 
licensed spectrum [12-14]. This could technically bring the emergence of CR technology and spectrum reuse to a halt. There exists a trade-off between the QoS provision and the associated pricing of the secondary radio spectrum that is enabled for reuse in SSMs [15-18]. The QoS [19-22] and economic robustness [23-28] of future SSMs have been two important topics of ongoing research on CR technology. Generally, revenue generation is core to the survival of SSMs [10].

This paper implements a secondary spectrum trade model based on a noncash approach. A new virtual token coined the spectrum dollar is proposed for the secondary spectrum trade. It is a unit incentive to be paid for the secondary radio spectrum trade-in SSMs. The spectrum dollar provides a methodology for revenue exchange among SSM entities without any involvement of a third party, such as banks, and helps to avoid the related incremental transaction costs. By its nature, the spectrum dollar is reminiscent of the application of the emerging tokenization concept in blockchain technology. A floor-and-trade rule is used to determine profitability shares based on the underlying secondary spectrum trading behaviours. This rule determines the exchange rate of spectrum dollars, the corresponding shares of trading PLOs, and participation fees to be charged by the SSM to maintain a no-loss situation for the spectrum broker managing the secondary radio spectrum trade. To maintain simplicity, in this research, the spectrum broker is assumed to be a nonprofit entity, and the focus of the study is on analysing the role of spectrum dollars as virtual tokens and their exchange based on the floor-and-trade rule for aiding secondary radio spectrum trade and pricing.

The floor is the threshold value determined by the spectrum broker to set the participation fees charged to trading PLOs for participation in the SSM, based on their adherence to the stipulated secondary spectrum trading behaviour for a given trading period. The participation fee not only forces the participating PLOs to enable spectrum reuse and avoid insurance of loss to the spectrum broker managing the trade but can also be used to generate revenues. It enlarges the profitability of the largest contributors and at the same time maximizes the loss of the lowest contributors in the SSM for a given period. This motivates participating PLOs to make their spectrum available for reuse in the SSM. The SSM generates revenues from the participation fee even if PLOs act maliciously to deny spectrum reuse. The model promises profit maximization to trading PLOs for sales maximization, subject to the satisfaction of spectrum demand in the SSM.

The rest of this paper is organized as follows. Section 2 discusses the related work. Section 3 introduces the system model for floor and trade rule and its advantages along with those offered by the use of spectrum dollars as a token for the secondary spectrum trade. The section is followed by the mathematical representation of the model in Section 4. The simulation results and analysis are provided in Section 5, and finally, conclusions are provided in Section 6.

\section{Related Work}

In general, we recognize two types of spectrum sharing schemes: centralized and distributed architectures. Within this paper, we focus our attention on the centralized scheme; although, the proposed scheme based on the application of the floor-and-trade rule can be easily extended to the distributed architecture. In centralized architecture, the spectrum broker is responsible for matching service requests from end-users with the spectrum bids of PLOs. The centralized architecture offers the prominent advantage of reduced complexity in terms of communication overhead, as there is no requirement of communication between end-users and PLOs. On the other hand, the centralized architecture could potentially suffer from a single point of failure, resulting in decreased efficiency of the SSM. Several solutions exist to overcome this issue, notably the proposal of a mirrored server architecture [29]. Instead of a single central server, for each SSM region, there could be multiple distributed servers, which are ready for the fail-over should the master server malfunction. Recently, blockchain technology took a step toward the wider application of such an architecture in various areas, including bioinformatics [30], the Internet of Things (IoT) [31, 32], and global payments [33]. In the spectrum sharing area, we have identified a few pioneering works proposing to use blockchain technology to enhance the efficiency of SSMs. Notably, [34] proposed the use of blockchain architecture for primary and secondary cooperative sharing, showing its advantages and drawbacks compared to the traditional database architecture. Security concerns related to spectrum sharing between aerial and terrestrial communications are addressed in [35]. The authors developed a secure spectrum trading and sharing scheme leveraging permissioned blockchain technology. In [36], the authors proposed a blockchain-based unlicensed spectrum sharing game, which allows a Nash equilibrium to be achieved among the operators by exchanging virtual cryptocurrency tokens. The blockchain technology used for spectrum sharing in the multiperator environment was considered in [37]. The authors proposed a smart contract to enable spectrum sharing while preserving the privacy of PLOs and the fairness of the system. Perhaps the conceptually closest paper to our contribution is this work presented in [38], where the authors proposed a two-stage privacy-preserving, incentive-compatible, and spectrum-efficient framework based on blockchain. The first stage involves the signing of a contract between the base station and end-users, for which the end-users receive a monetary bonus paid in cryptocurrency. The second stage involves mapping the available shared spectrum among the machineto-machine (M2M) communication entities. Our paper also presents a two-stage mechanism. In the first stage, the spectrum broker collects the available spectrum resources from PLOs, while in the second stage, it managed the sealed bid auction process to match secondary spectrum requests and bids. It should be noted, however, that the revenues from the SSM are paid in noncash monetary units coined spectrum dollars. This approach naturally avoids the need for high transaction costs and the presence of intermediaries and eventually produces market efficiency. Due to its noncash nature, the latter part of our approach could be implemented by using a well-known public or application-specific permissioned blockchain, while the spectrum broker as the centralized entity would still be responsible for sustaining market 


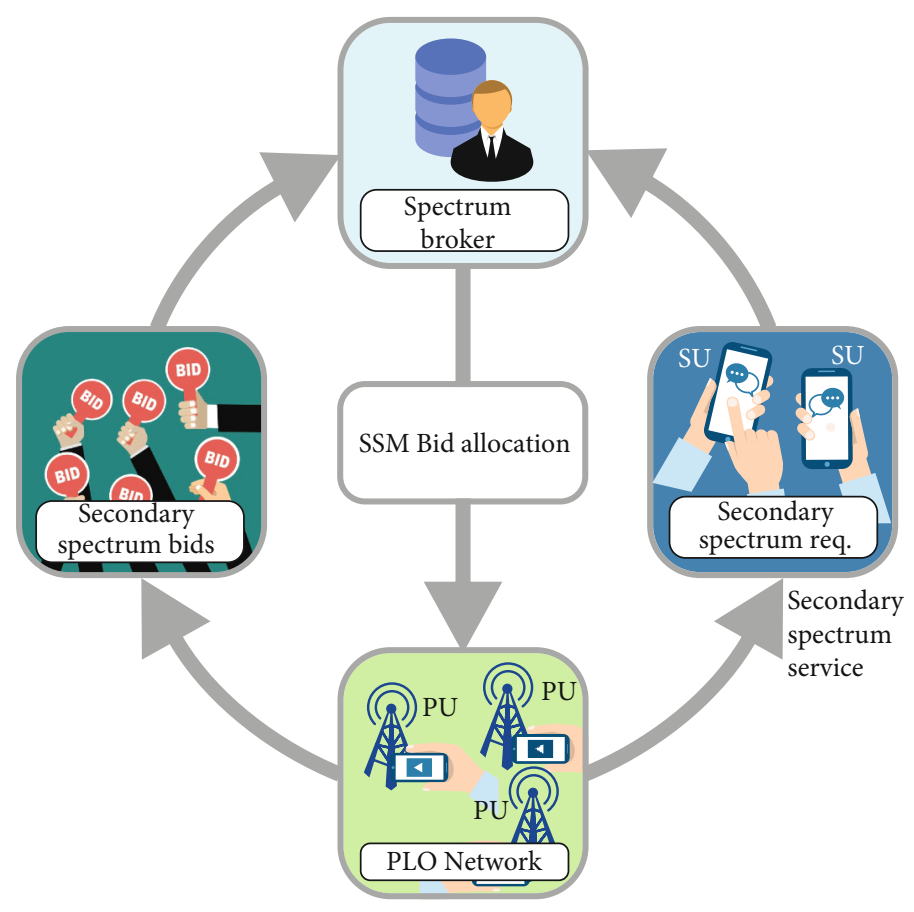

FIGURE 1: Secondary spectrum trade managed by a centralized spectrum broker.

equilibrium and providing a FIAT gateway exchange (spectrum dollar/USD) for PLOs.

\section{The Proposed Trade Model}

Figure 1 presents the scenario of a secondary radio spectrum trade model managed by a centralized spectrum broker. PLOs place their sealed bids specifying the amount of spectra and corresponding prices with the spectrum broker, which governs the auctioning process and takes responsibility for making the bid allocations. Based on supply and demand, PLOs trade their radio spectra to generate revenues for providing services to secondary users in the SSM. The spectrum auction process (i.e., secondary spectrum bids, spectrum broker, and SU requests) has been modelled as a sealed-bid spectrum auction as proposed in $[7,39]$. The focus of this work is on revenue redistribution and facilitation among the SSM entities. The model developed in this research has been implemented over a trading horizon that comprises several periods of secondary radio spectrum trade. PLOs compete with each other for spectrum trade opportunities in the SSM. The floor value is a nonnegative number that determines the participation fee in spectrum dollars based on the total amount of money exchanged among participating PLOs. The floor value is also used to price the spectrum dollar and determine the corresponding profit-loss shares for participating PLOs to enable radio spectrum reuse. Spectrum dollars are proposed to be exchangeable among participating PLOs over the trade horizon. For this purpose, a token exchange block has been introduced to enable the exchange of spectrum dollars among PLOs to either buy (accumulate) enough spectrum dollars to meet the floor value or to sell spectrum dollars to convert their earnings as profit into FIAT money. The spectrum dollar exchange based on the floor value keeps the secondary spectrum trade fair [40].

The floor value set by the spectrum broker based on the underlying secondary spectrum trade is used to determine whether a participating PLO made a profit or a loss in a given secondary radio spectrum trading period. All trading PLOs must pay the participating fee equivalent to the floor value to the spectrum broker in spectrum dollars. Loss-making PLOs must purchase the spectrum dollars from profitable PLOs to make up the difference between their respective earnings and the set floor value (i.e., the participation fee) for a given trading cycle. This purchase enables loss-making PLOs to make their payments for trading in the SSM to the spectrum broker in spectrum dollars. The number of spectrum dollars to be exchanged by participating PLOs is used to set the price for the spectrum dollar using the demand-supply equilibrium principle. The number of spectrum dollars purchased by a loss-making PLO for a given trading cycle at the current spectrum dollar price in the SSM determines its total loss. Similarly, the number of excess spectrum dollars of profitable PLOs for a given trading period at the current spectrum dollar price in the SSM determines their respective profitability for the given trading period.

The key aspect of the proposed platform is the tokenization (with the spectrum dollar acting as the token) of the spectrum, which allows for the opening of the spectrum sharing market without intermediaries and with additional control by the regulator (the spectrum broker). In the proposed model, the token exchange block can be realized as the traditional FIAT gateway exchange block in blockchain, while the spectrum broker is a separate entity placed outside the blockchain model. This hybrid (blockchain application and 


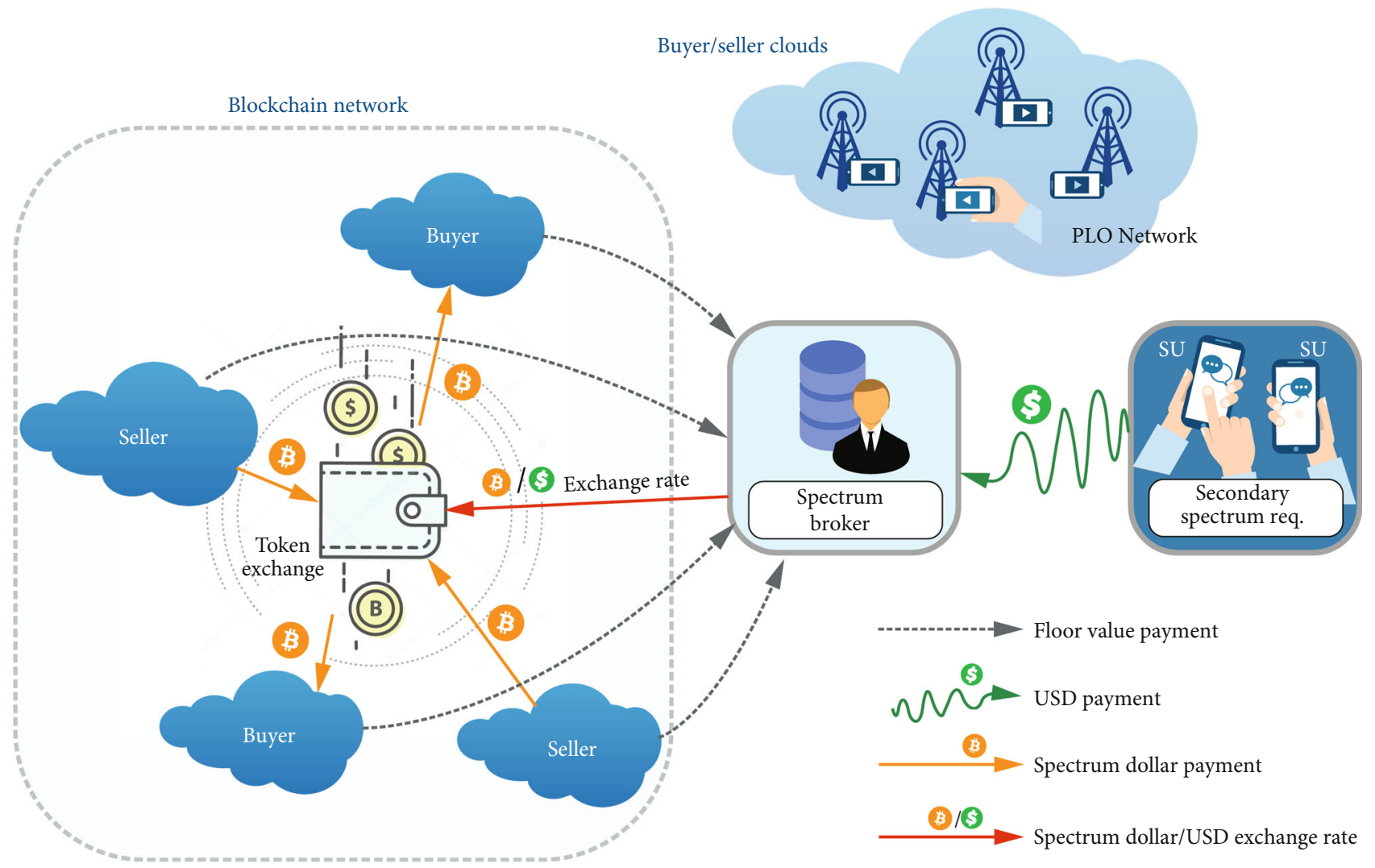

FIGURE 2: Block diagram of the proposed spectrum secondary market with USD and spectrum dollar transaction flows.

centralized control mechanism) scheme has already been considered in several studies, including [37]. It should also be noted that we reserve the examination of numerous details regarding the blockchain implementation (consensus mechanisms, selection of public (permissioned) blockchain, hyperledger, etc.) for our future research and place our main attention in this paper on the study of the entire demand/supply chain at large.

3.1. Advantages of the Floor-and-Trade Rule. The proposed system model is based on the floor-and-trade rule, which provides several advantages to the trading process in the SSM, which are explained below.

(i) The floor-and-trade rule enables an automated methodology to impose a secondary spectrum withholding charge on PLOs and ensure their participation and spectrum utilization efficiency

(ii) The floor-and-trade methodology increases the chances of secondary spectrum availability by enforcing the participation of PLOs in the SSM to enable radio spectrum reuse

(iii) The automation of profit-loss calculations as revenue shares of the participating entities reduces the monitoring overhead for secondary spectrum trade reporting by PLOs. Further possibilities for false secondary spectrum trade values are minimized through the use of a spectrum withholding charge such as the participation fee in the SSM

(iv) There are no added operational costs (other than infrastructure sharing cost, if any) for the spectrum broker/SSMto enable and manage the secondary radio spectrum trade in a highly competitive manner using the floor-and-trade methodology

(v) The floor-and-trade methodology maximizes the profitability shares of the highest-contributing PLOs, and at the same time, it maximizes the loss of the lowest-contributing PLOs

(vi) The floor-and-trade rule minimizes the chances of possible economic malpractice involving participating PLOs manipulating secondary spectrum pricing. This avoids the establishment of a monopoly over the enabled secondary spectrum

(vii) The use of the spectrum dollar can enable benefits transfer among the entities belonging to SSMs of different sizes in a direct manner without requiring any involvement by third parties, such as banks, and hence avoids transaction costs incurred to the third parties

The block diagram of interaction among all SSM entities using the spectrum dollar and USD transactions is depicted in Figure 2. 
TABLE 1: Notation for the different parameters in the floor-and-trade rule-based exchange methodology.

\begin{tabular}{|c|c|}
\hline Notation & Parameters \\
\hline$h$ & Instant trading period in the SSM. \\
\hline$H$ & Trade horizon in the SSM. \\
\hline$n$ & Total number of participating PLOs in the SSM. \\
\hline Revenue $_{i, h}^{S \$}$ & Revenue in spectrum dollars for participating PLO i for a given $h$. \\
\hline $\operatorname{Revenue}_{j, h}^{S \$}$ & Revenue in spectrum dollars for participating PLO j for a given $h$. \\
\hline Total Revenue ${ }_{H}^{S \$}$ & Total revenue of $n$ PLOs from secondary spectrum trade for a given $H$. \\
\hline Floor $_{H}$ & Floor value for exchange of spectrum dollars among $n$ PLOs for a given $H$. \\
\hline Seller & Spectrum dollar seller for a given trade horizon $H$. \\
\hline Buyer & Spectrum dollar buyer for a given trade horizon $H$. \\
\hline$\sum_{h=1}^{H}$ Revenue $_{\text {Seller }, h}^{S \$}$ & Total revenue of a spectrum dollar seller in the SSM for a given trade horizon $H$. \\
\hline$\sum_{h=1}^{H}$ Revenue $_{\text {Buyer }, h}^{S \$}$ & Total revenue of a spectrum dollar buyer in the SSM for a given trade horizon $H$. \\
\hline$P_{H}^{S \$}$ & Spectrum dollar price for a given trade horizon $H$. \\
\hline Profitability $y_{i}^{U S D}$ & Profitability of participating PLO i in USD for a given trade horizon $H$. \\
\hline Total Sellers ${ }_{H}$ & Number of spectrum dollar sellers in the SSM for a given trade horizon $H$. \\
\hline Total Buyers $_{H}$ & Number of spectrum dollar buyers in the SSM for a given trade horizon $H$. \\
\hline
\end{tabular}

\section{Analytical Model for the Floor-and- Trade Rule}

In this section, the fundamental relations between the spectrum dollar supply and demand and the corresponding equations are outlined. Let Revenue $e_{i, h}^{S \$}$ and Revenue ${ }_{j, h}^{S \$}$ represent $^{-}$ the revenue in spectrum dollars for trading PLO $i$ and PLOj, respectively, for a given instant trading period. Let Total Re venue $_{H}^{S \$}$ represent the total revenue of all trading PLOs in terms of spectrum dollars over a given trading horizon. Let Floor $_{H}$ represent the floor value for exchange of spectrum dollars among the $n$ PLOs trading in the SSM. A PLO is a spectrum dollar seller if its revenue generation over a com-

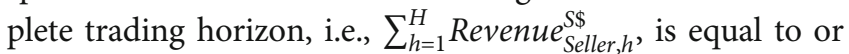
greater than the floor value determined by the spectrum broker for a given bidding instant. Similarly, a PLO is a spectrum dollar buyer if its revenue generation over a complete trading horizon in spectrum dollars, i.e., $\sum_{h=1}^{H} \operatorname{Revenue}_{B u y e r, h}^{S \$}$, is less than the floor value set in the SSM for the given trading period. Let $P_{H}^{S \$}$ be the price calculated for the exchange of a unit spectrum dollar and Profitalability ${ }_{i}^{U S D}$ be the profitability of a participating PLO in US dollars, for a given trading horizon. Let the total number of spectrum dollar seller be represented by Total Sellers $s_{H}$. Also, let the number of spectrum dollar buyers be represented by TotalBuyers Ti.e., $T$ otal Buyers $_{H}=n-$ Total Sellers $_{H}$ ).

Table 1 provides the notation for the different parameters involved in the implementation of the floor-and-trade rulebased spectrum dollar exchange methodology. The revenue of an individual trading PLO in spectrum dollars is calculated as the sum of its revenue generation over all trading periods of a given trading horizon $H$, as given in Eq. (1)

$$
\operatorname{Revenue~}_{i, H}^{S \$}=\sum_{h=1}^{H} \operatorname{Revenue~}_{i, h}^{S \$} .
$$

Total Revenue ${ }_{H}^{S \$}$ is the sum of revenues generated by individual PLOs over all trading periods of a given trading horizon $H$, as given in Eq. (2).

$$
\text { Total Revenue }_{H}^{S \$}=\sum_{h=1}^{H} \sum_{i=1}^{n} \text { Revenue }_{i, h}^{S \$} .
$$

The floor value is determined by the spectrum broker by dividing the total revenues generated by the total number of PLOs trading in the SSM, as given in Eq. (3)

$$
\text { Floor }_{H}=\frac{\text { Total Revenue }_{H}^{S \$}}{n} .
$$

The selling/buying status of each PLO trading in the SSM is determined by calculating the difference between its earnings and the specified floor value for a given trading horizon. This helps to determine the total number of spectrum dollar sellers and buyers for a given trade horizon $H$ as follows:

$$
\begin{aligned}
& \text { Total Sellers }_{H}=\text { Total Sellers }_{H}+1 \text {, if Revenue } \text { Ri,H }_{\$}^{\$}-\text { Floor }_{H} \geq 0 \\
& \text { Total Buyers }_{H}=\text { Total Buyers }_{H}+1 \text {, if Revenue }{ }_{i, H}^{\$ \$}-\text { Floor }_{H}<0
\end{aligned}
$$


Upon the completion of a trade horizon, each trading PLO, whether a buyer or a seller, pays an amount equal to the current floor value to the SSM as a participation fee. At market equilibrium, the total supply of spectrum dollars is equal to their total demand in the SSM, as given in Eq. (5)

$$
\begin{aligned}
\sum_{\text {Buyer }=1}^{\text {Total Buyers }} & \left(\text { Floor }_{H}-\text { Revenue }_{\text {Buyer }, H}^{S \$}\right) \\
& =\sum_{\text {Seller }=1}^{\text {Total Sellers }}\left(\text { Revenue }_{\text {Seller }, H}^{S \$}-\text { Floor }_{H}\right),
\end{aligned}
$$

where $\sum_{\text {Buyer }=1}^{\text {Total Buys }}\left(\right.$ Floor $_{H}-$ Revenue $_{\text {Buyer }, H} \$$ is the spectrum dollar demand function, while the spectrum dollar supply function is given as $\sum_{\text {Seller }=1}^{\text {Total Sellers }}\left(\right.$ Revenue $_{\text {Seller }, H}^{S \$}-$ Floor $\left._{H}\right)$. These functions provide the total number of spectrum dollars to be exchanged among trading PLOs for a given trading horizon. We would like to stress the fact that the expressions given in Eq. (5) comprise two important contributions. The cumulative sum of spectrum dollars, available for sale with Total Sellers $_{H}$ is given by $\sum_{\text {Seller }=1}^{\text {Total Sellers Revenue }}$ Seller,$H_{\text {. Also, }}^{\text {S }}$. there are Total Sellers ${ }_{H} \times$ Floor $_{H}$ spectrum dollars with the selling PLOs that are not available for sale but must be paid to the SSM as participation fees. Similarly, the cumulative sum of spectrum dollars to be purchased by the Total Buye $r s_{H}$ in the SSM is given by $\sum_{\text {Buyer }=1}^{\text {Total Buyers }}$ Revenue $_{\text {Buyer, }}^{S \$}$. Addi-

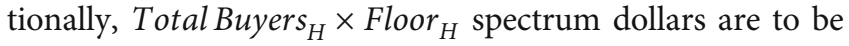
paid by the buying PLOs to the SSM. Therefore, Eq. (5) can also be rewritten as Eq. (6)

$$
\begin{gathered}
\sum_{\text {Seller }=1}^{\text {Total Sellers }}\left(\text { Revenue }_{\text {Seller }, H}^{\text {R }}\right)-{\text { Total Sellers } \times \text { Floor }_{H}} \\
=\text { Total Buyer }_{H} \times \text { Floor }_{H} \\
-\sum_{\text {Buyer }=1}^{\text {Total Buyers }}\left(\text { Revenue }_{\text {Buyer }, H}^{S \$}\right) .
\end{gathered}
$$

The price of a unit spectrum dollar in USD can be determined by using either side (the demand or the supply functions) of Eq. (6)

$$
\begin{aligned}
P_{H}^{S \$} & =\sum_{\text {Seller }=1}^{\text {Total Sellers }}\left(\text { Revenue }_{\text {Seller }, H}^{S \$}\right)-\left(\text { Total Sellers }_{H} \times \text { Floor }_{H}\right) \\
& =\left(\text { Total Buyer }_{H} \times \text { Floor }_{H}\right)-\sum_{\text {Buyer }=1}^{\text {Total Buyers }}\left(\text { Revenue }_{\text {Buyer }, H}^{S \$}\right),
\end{aligned}
$$

where Floor $_{H}$ is given by Eq. (3) and Eq. (7) provides the optimum spectrum dollar price in the SSM based upon the total number of buyers/sellers and the floor price, while the floor price is based on total revenue and the total number of participants. The spectrum dollar price decreases with an increase in the quantity supplied and increases with an increase in the quantity demanded, and vice versa. Let
Profitability $_{i}^{U S D}$ represent the profitability in USD for a participating PLO $i$ in the SSM. We can express its quantity as given by Eq. (8)

$$
\text { Profitability }_{i}^{U S D}=P_{H}^{S \$} \times\left(\text { Revenue }_{i, H}^{S \$}-\text { Floor }_{H}\right) \text {. }
$$

Profitability ${ }_{i}^{U S D}$ results in a negative value for PLOs that make a loss in the SSM for a given trade horizon. Figure 3 presents the flowchart for the spectrum dollar unit price and revenue calculation (in spectrum dollars). These metrics determine PLO profitability in USD at the end of the process.

\section{Simulation Results and Analysis}

5.1. Preliminaries. The proposed system is based on a periodic one-shot sealed-bid auction [41]. We consider two established spectrum-sharing techniques: (a) the carrotand-stick-based allocation technique [17] and (b) the QoSbased allocation technique [18]. The revenue information of these two models is assumed to be released in spectrum dollars to enable the implementation of the floor-and-trade methodology in this work. In the simulations for both models, a uniform distribution of break-even prices has been used, and SSM participation will be valued for each individual participating PLO for a total of ten participating PLOs in the simulations. The optimum bidding price is calculated based on the sum of the probability of a participating PLO winning a bid either on or below the margin using the uniformly distributed break-even prices. The description of the spectrum auction bidding process is beyond the scope of this paper, and interested readers can find it in [17]. The model considers the PLO's will to participate in the SSM to determine its level of participation and its break-even cost as the reserve price below which it decides against a sale in the SSM. Hence, all participating PLOs do not offer all of the spectrum spaces available to the SSM due to the economic parameters. The allocations are performed after the auctioning process, that is, after the determination of the winners, the secondary spectrum pricing, and the related payments. Participating PLOs that win the bids either on or below the margin generate revenues in the SSM, while those that lose the bids do not get the opportunity to generate any revenue at that bidding instant but may participate in future bids. PLOs' profitability is calculated as the revenues that are generated beyond their break-even costs. The simulations were run for a complete bidding horizon containing 24 bidding instants, each corresponding to an hourly bid in the SSM.

5.2. Simulation and Results. Figure 4 presents the Total Rev $e^{\text {enue }}{ }_{H}^{\$}$ calculated in spectrum dollars using Eq. (3) for ten PLOs participating in the SSM trade. The graph shows that the total revenue of the participating PLOs is higher for the QoS optimization-based secondary spectrum access model than that for carrot-and-stick model. This is because the carrot-and-stick model considers only quantity [17], while the QoS-based methodology considers both the quantity and quality of the traded spectrum during the bid allocation process. Pricing of the bids considering both quantity and 


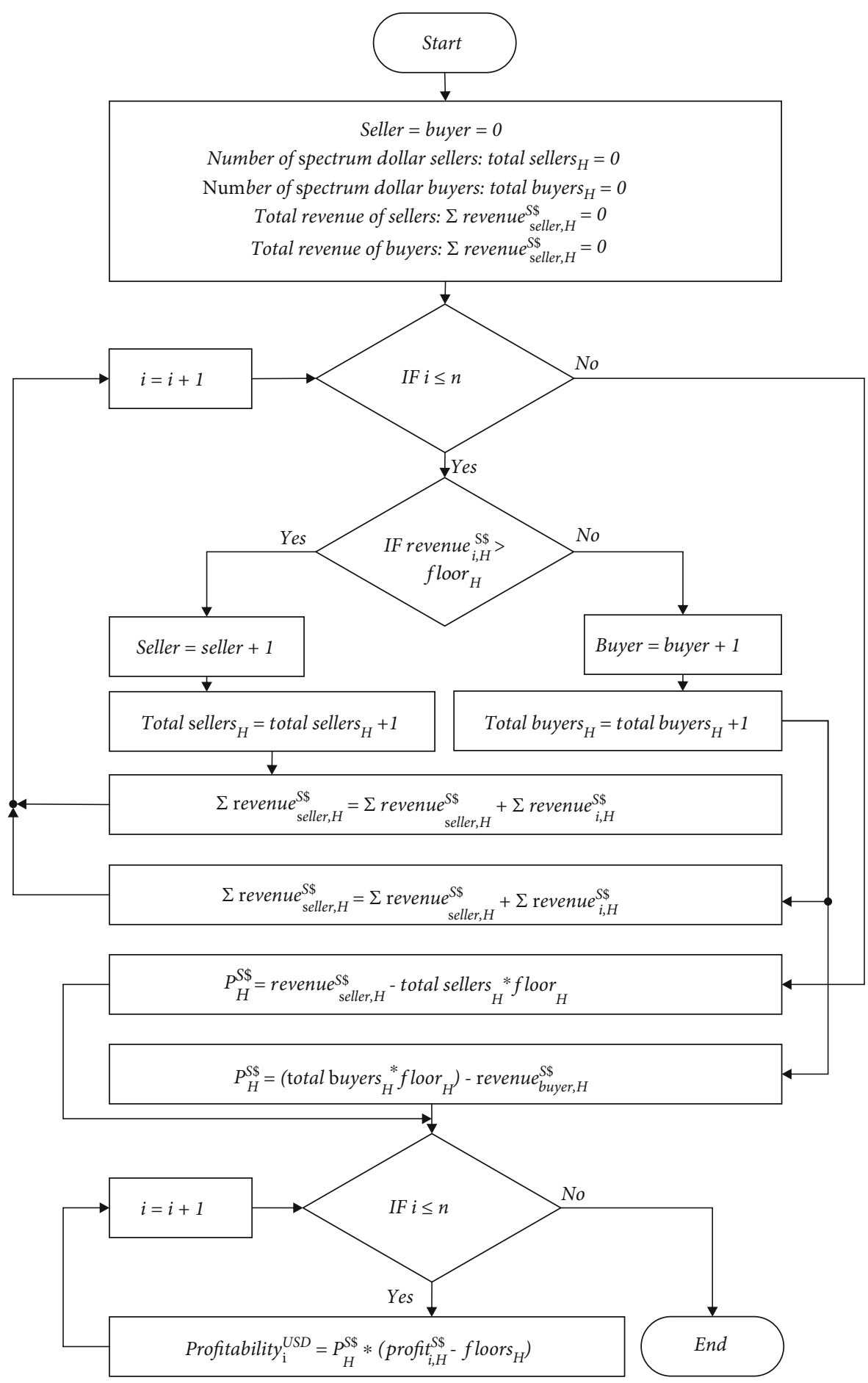

FIGURE 3: Flowchart for the spectrum dollar price and the revenue calculation in USD using the floor-and-trade rule.

quality increases the associated unit secondary spectrum costs in the SSM as proven in [18]. The corresponding revenues generated by each of the trading PLOs for the given trading horizon are shown in Table 2. PLOs 2, 5, 7, and 10 were unable to win any bids during the bidding horizon due to their high break-even costs, and hence, the bidding prices did not generate any revenue over the horizon. Moreover, it can be observed that for the QoS-based allocation model, the spectrum dollar price $P_{H}^{S \$}$ is higher, and at the same time, the number of spectrum dollars to be exchanged is higher as well. This confirms the theoretical foundation laid in Section 3.

The respective floor values Floor $_{H}$ for the total revenues generated by each model are shown in Figure 5. It can be seen that an increase in the floor value is proportionate to the respective total revenue values in spectrum dollars for each 


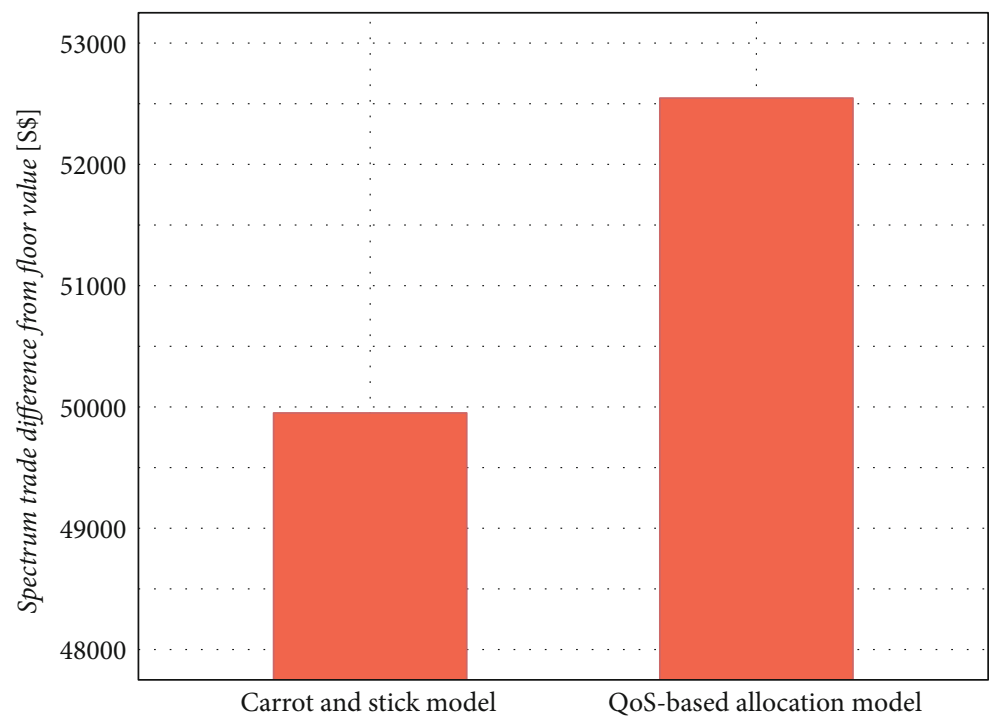

FIgURE 4: Total revenue of all participating PLOs in spectrum dollars for the secondary radio spectrum trade.

TABle 2: Revenue for individual participating PLOs and total revenue for one trading horizon in the SSM.

\begin{tabular}{lcc}
\hline PLO \# & $\begin{array}{c}\text { Revenue for carrot-and- } \\
\text { stick model (S\$) }\end{array}$ & $\begin{array}{c}\text { Revenue for QoS-based } \\
\text { allocation model (S\$) }\end{array}$ \\
\hline 1 & 6925.09 & 5796.11 \\
2 & 0 & 0 \\
3 & 8605.64 & 7146.72 \\
4 & 958.55 & 4626.51 \\
5 & 0 & 0 \\
6 & 12378.8 & 9830.56 \\
7 & 0 & 0 \\
8 & 9948.94 & 9909.52 \\
0 & 11133.58 & 15236.64 \\
10 & 0 & 0 \\
Total & $\mathbf{4 9 9 5 0 . 6}$ & $\mathbf{5 2 5 4 6 . 0 6}$ \\
revenue & &
\end{tabular}

trade model. This means that the higher the total revenue is, the higher the calculated floor value given the same number of PLOs trading in the SSM; thus, the QoS-based model has a higher floor value.

Comparing the revenues generated by each PLO to the corresponding floor value of each model, it can be seen that in both cases, 5 PLOs generated more revenues from SSM trade than the current floor value and are hence profitable, while the other 5 PLOs, which generated less revenue than the floor value, make a loss. Using the values for total revenue in spectrum dollars, floor values, and the number of spectrum dollar sellers and buyers, the spectrum dollar price is determined using either the demand or the supply function given in Eq. (8). The results are shown for both spectrum allocation methodologies in Table 3.

The corresponding revenue generated by each of the participating PLOs in the SSM trade for the trading horizon using the carrot and stick-based secondary spectrum trade model, with a floor value Floor $_{H}=4995.06$ and respective spectrum dollar price $P_{H}^{S \$}=24975.29$, is shown in Table 4 . The sum of the profit/loss values for the secondary spectrum trade in the SSM for a given trade horizon is zero, which confirms the theoretical expectation introduced in Section 3.

Similarly, the same simulation scenario using the QoS optimization-based trade model is given in Table 5 . In this case, the floor value Floor $_{H}=5254$ and respective spectrum dollar price $P_{H}^{S \$}=26273$, as shown in Table 5 .

To obtain more generalized results, the number of trading PLOs in the SSM was increased to one hundred $(n=100)$, which trade different numbers of spectrum spaces. The floor value for $n=100$ trading PLOs was calculated to be Floor $_{H}=55$, with 46 PLOs as sellers and the other 54 PLOs as the buyers of spectrum dollars. As shown in Table 6, the unit spectrum trade price in the SSM is set to unity, generating Total Revenue ${ }_{H}^{S \$}=5072$ spectrum dollars, with the spectrum dollar price equal to $P_{H}^{S \$}=2860$ USD.

Figure 6 shows PLOs' spectrum trade values relative to the floor value set in the SSM, while Figure 7 shows the corresponding relative revenue in USD for PLOs trading under the floor-and-trade methodology. The profitability shares of participating PLOs in USD depend upon their respective revenue differences in spectrum dollars from the floor value. The spectrum dollar price is calculated based on the demand and supply equilibrium value of spectrum dollars (for example, PLO 16 in Figure 7) at which participating PLOs make neither a profit nor a loss; in other words, the price trades the spectrum slots at a value exactly equal to the floor value in the SSM.

5.3. Sensitivity Analysis. A sensitivity analysis was performed on the proposed floor-and-trade model to analyse the effects of variation in the individual parameters. Some of the findings of the sensitivity analysis are as follows: 


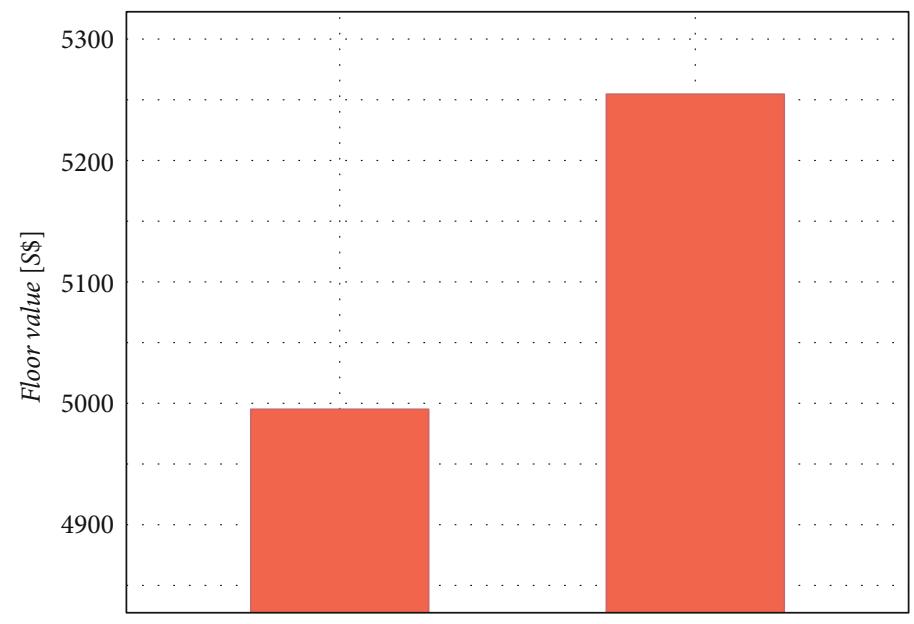

Carrot and stick model $\quad$ QoS-based allocation model

FIGURE 5: Floor values for each secondary spectrum trade methodology in the SSM.

TABLE 3: Revenue in spectrum dollars, respective floor values, and spectrum dollar prices for each secondary spectrum trade methodology.

\begin{tabular}{lcc}
\hline Parameter & $\begin{array}{c}\text { Carrot-and-stick } \\
\text { model }\end{array}$ & $\begin{array}{c}\text { QoS-based } \\
\text { allocation model }\end{array}$ \\
\hline $\begin{array}{l}\text { Total spectrum dollars } \\
\text { (S\$) }\end{array}$ & 49950.6 & 52546.06 \\
$\begin{array}{l}\text { PLOs participating in the } \\
\text { SSM }\end{array}$ & 10 & 10 \\
$\begin{array}{l}\text { Floor value } \\
\text { No.of spectrum dollar } \\
\text { sellers }\end{array}$ & 4995.06 & 5254.60 \\
$\begin{array}{l}\text { No.of spectrum dollar } \\
\text { buyers }\end{array}$ & 5 & 5 \\
$\begin{array}{l}\text { No.of spectrum dollar to } \\
\text { exchange }\end{array}$ & 24975.3 & 5 \\
$\begin{array}{l}\text { Spectrum dollar price } \\
\text { (USD) }\end{array}$ & 24975.29 & 26273 \\
\hline
\end{tabular}

TABle 4: Revenue, respective difference with floor value, and profit/loss made by each participating PLO using the carrot and stick-based trade model.

\begin{tabular}{lccc}
\hline $\begin{array}{l}\text { PLO } \\
\#\end{array}$ & $\begin{array}{c}\text { Revenue } \\
(\mathrm{S} \$)\end{array}$ & $\begin{array}{c}\text { Difference from floor } \\
(\mathrm{S} \$)\end{array}$ & $\begin{array}{c}\text { Profit/loss made } \\
(\mathrm{S} \$)\end{array}$ \\
\hline 1 & 6925.09 & 1930.03 & 48203078.26 \\
2 & 0 & -4995.06 & -124753122 \\
3 & 8605.64 & 3610.58 & 90175318.67 \\
4 & 958.55 & -4036.51 & -100813048.2 \\
5 & 0 & -4995.06 & -124753122 \\
6 & 12378.8 & 7383.74 & 184411121.6 \\
7 & 0 & -4995.06 & -124753122 \\
8 & 9948.94 & 4953.88 & 123724639.2 \\
9 & 11133.58 & 6138.52 & 153311378.6 \\
10 & 0 & -4995.06 & -124753122 \\
\hline
\end{tabular}

TABLE 5: Revenue, respective difference with floor value, and profit/loss made by each participating PLO using the QoS optimization-based trade model.

\begin{tabular}{lccc}
\hline $\begin{array}{l}\text { PLO } \\
\#\end{array}$ & $\begin{array}{c}\text { Revenue } \\
(\mathrm{S} \$)\end{array}$ & $\begin{array}{c}\text { Difference from floor } \\
(\mathrm{S} \$)\end{array}$ & $\begin{array}{c}\text { Profit/loss made } \\
(\mathrm{S} \$)\end{array}$ \\
\hline 1 & 5796.11 & 541.504 & 14226950.84 \\
2 & 0 & -5254.606 & -138054421.1 \\
3 & 7146.72 & 1892.114 & 49711567.89 \\
4 & 4626.51 & -628.096 & -16501985.05 \\
5 & 0 & -5254.606 & -138054421.1 \\
6 & 9830.56 & 4575.954 & 120224176.7 \\
7 & 0 & -5254.606 & -138054421.1 \\
8 & 9909.52 & 4654.914 & 122298695.2 \\
9 & 15236.64 & 9982.034 & 262258278.7 \\
10 & 0 & -5254.606 & -138054421.1 \\
\hline
\end{tabular}

TABLE 6: Floor-and-trade simulation for 100 trading PLOs in the SSM.

\begin{tabular}{lcccc}
\hline $\begin{array}{l}\text { No. of } \\
\text { PLOs }\end{array}$ & $\begin{array}{l}\text { No. of } \\
\text { sellers }\end{array}$ & $\begin{array}{c}\text { Total } \\
\text { revenue }(S \$)\end{array}$ & $\begin{array}{c}\text { Floor } \\
\text { value }\end{array}$ & $\begin{array}{c}\text { Spectrum dollar } \\
\text { price (USD) }\end{array}$ \\
\hline 100 & 48 & 5500 & 55 & 2860 \\
\hline
\end{tabular}

(i) The floor value increases with an increase in total revenue earnings, while it decreases with an increase in the number of PLOs trading in the SSM

(ii) The spectrum dollar price increases with an increase in the floor value, and vice versa

(iii) The spectrum dollar price and the profitability shares of all participating PLOs in USD are zero, with all participating PLOs being sellers and none being buyers in the SSM. This is intuitive, as in this case, the earnings for each of the participating PLOs are equivalent to the floor value, and there are no spectrum dollars to exchange 


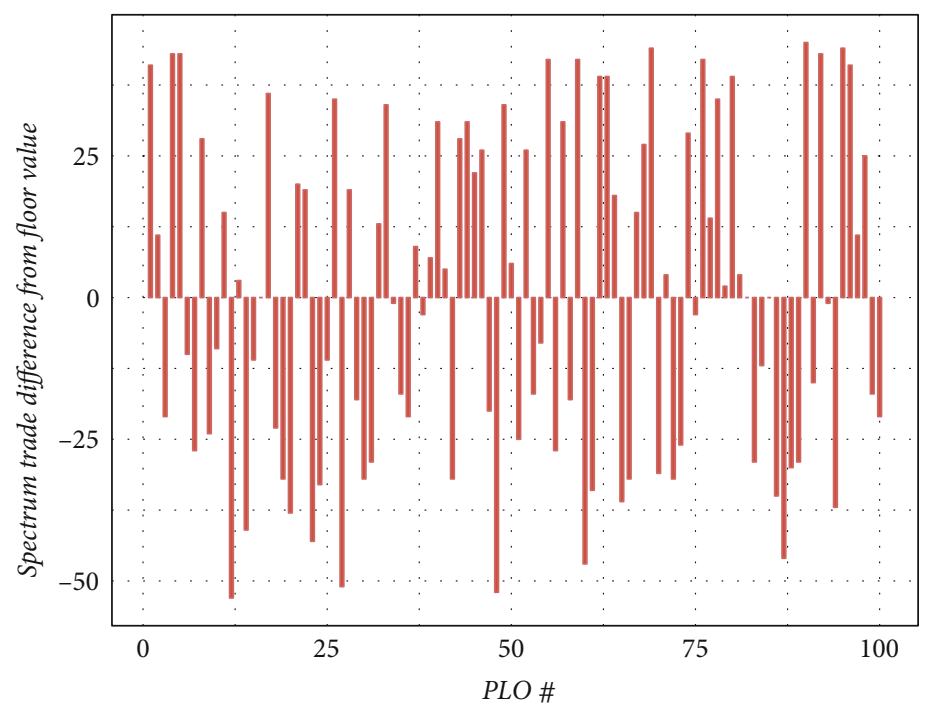

FIgURE 6: Spectrum trade by PLOs relative to the floor value.

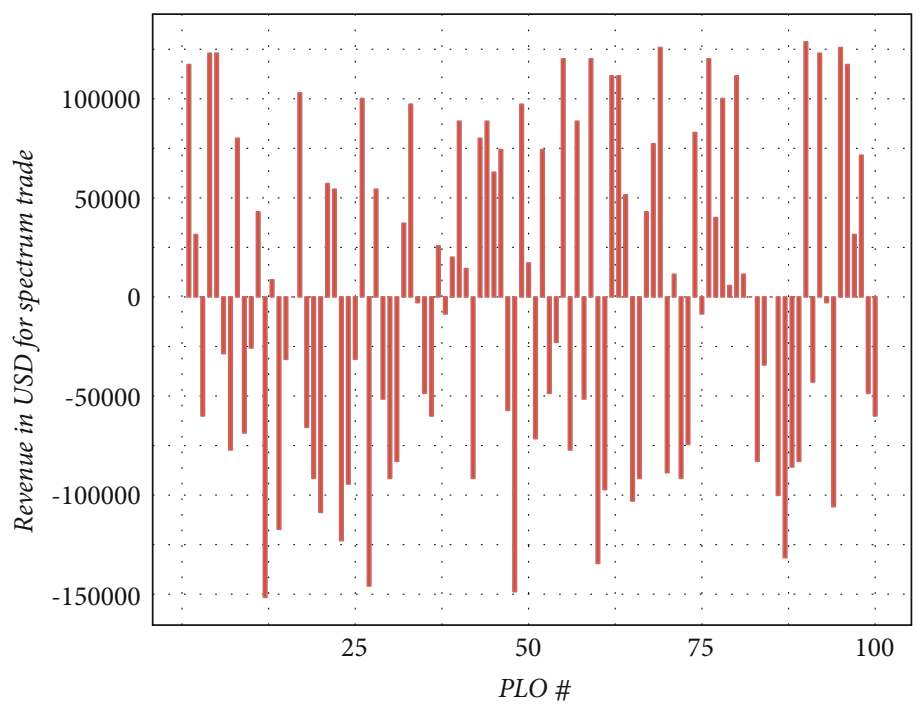

FIGURE 7: Revenue in USD for spectrum trade by PLOs relative to the floor value.

(iv) The spectrum dollar price is highest when there are no spectrum dollar sellers and all participating PLOs are spectrum dollar buyers

The floor-and-trade methodology automates a valuebased reward-and-punishment mechanism for the underlying secondary spectrum trade. The highly competitive environment for the exchange of spectrum dollars using the floor-and-trade methodology maximizes the reward of the participating PLOs that bring the most value to the SSM. It simultaneously maximizes the punishment of those that withhold access to their available spectrum for secondary use. The participation fee and spectrum dollar price are calculated in real-time based on the underlying secondary spectrum trade behaviours in the SSM.

\section{Conclusions}

We have proposed a blockchain-based model of a secondary spectrum market based on spectrum dollar tokens. In the proposed model, the floor-and-trade rule is applied to regulate spectrum dollar pricing depending on the performance of the overall trade in the SSM rather than that of individual PLOs. The spectrum dollar price increases with a decrease in the number of spectrum dollar sellers or an increase in the number of spectrum dollar buyers, and vice versa. The floor-and-trade rule-based methodology maximizes the reward for the largest contributors and simultaneously maximizes the punishment for those making the smallest contributions to enabling radio spectrum reuse. The automated process of the floor-and-trade rule-based methodology 
minimizes the monitoring overhead of secondary spectrum trade reporting. Spectrum dollar pricing and exchange minimize the control of participating PLOs over the economic parameters of the underlying secondary spectrum trade. PLOs cannot manipulate the economic parameters of the secondary spectrum trade, and hence, the chances for the establishment of a monopoly over the secondary spectrum resource are annulled. SSMs can base their secondary spectrum allocations purely on the QoS values offered to them. In the future, SSMs may decide to sell their earnings to meet their operating costs and/or make capital investments to enable radio spectrum reuse.

\section{Data Availability}

The data used to support the findings of this study have been deposited in the Hindawi repository on github repo (https:// github.com/JurajGazda/Hindawi).

\section{Conflicts of Interest}

The authors declare no conflict of interest regarding this publication.

\section{Acknowledgments}

This research was funded by the Slovak Research and Development Agency, projects APVV-18-0214 and APVV15-0055 and by the Scientific Grant Agency of the Ministry of Education, Science, Research and Sport of Slovakia under the contract VEGA 1/0268/19. This research was also supported by Ukrainian government project No.0120U100674 "Designing the novel decentralized mobile network based on blockchain architecture and artificial intelligence for 5G/6G development in Ukraine".

\section{References}

[1] E. Hossain, D. Niyato, and Z. Han, "Dynamic Spectrum Access and Management in Cognitive Radio Networks," Books 24x7, Cambridge university press, 1st edition, 2005.

[2] V. Mishra, L. C. Tong, and C. Syin, "QoS based spectrum decision framework for cognitive radio networks," in 18th IEEE International Conference on Networks (ICON), 2012.

[3] D. S. Aldar, "Centralized integrated Spectrum sensing for cognitive radios," International Journal of Computer Science and Communication, vol. 1, no. 2, pp. 227-229, 2010.

[4] M. Khan, B. Altaf, and M. Moghal, Introduction, Decision Making Techniques for Cognitive Radios, Lambert Acad. Publishing, 1st edition, 2012.

[5] M. R. Moghal, M. A. Khan, and H. A. Bhatti, "Spectrum optimization in cognitive radios using elitism in genetic algorithms," in 2010 6th International Conference on Emerging Technologies (ICET), pp. 49-54, IEEE, 2010.

[6] T. Maksymyuk, M. Brych, M. Klymash, and M. Jo, "Cooperative channels allocation in unlicensed spectrum for D2D assisted 5G cellular network," in 2017 2nd International Conference on Advanced Information and Communication Technologies (AICT), pp. 197-200, 2017.
[7] M. A. Khan and S. Ahmed, Decision Making Techniques in Cognitive Radios, Lambert Publishing, 2008.

[8] I. F. Akyildiz, W.-Y. Lee, M. C. Vuran, and S. Mohanty, "NeXt generation/dynamic spectrum access/cognitive radio wireless networks: a survey," Computer Networks, vol. 50, no. 13, pp. 2127-2159, 2006.

[9] P. Pawelczak, Opportunistic Spectrum Access: Designing link and transport layer, Dept. of Telecommunications, TU Delft Univ. of Tech, 2009.

[10] P. R. Gronsund, O. Grondalen, and M. Lahteenoja, "Business case evaluations for LTE network offloading with cognitive femtocells," Telecommunications Policy, vol. 37, no. 2-3, pp. 140-153, 2013.

[11] P. R. Gronsund, Cognitive Radio from a Mobile Operators Perspective: System Performance and Business Case Evalua- Tions, Doctoral Dissertation, Mathematics and Natural Sciences Dept., Univ of Oslo, 2013.

[12] D. Horváth, V. Gazda, and J. Gazda, "Agent-based modeling of the cooperative spectrum management with insurance in cognitive radio networks," EURASIP Journal on Wireless Communications and Networking, vol. 2013, no. 1, 2013.

[13] O. Raoof, Z. Al-Banna, and H. S. Al-Raweshidy, "Competitive Spectrum Sharing in Wireless Networks: A Dynamic NonCooperative Game Approach," in Wireless and Mobile Networking, pp. 197-207, IFIP Advances in Information and Communication Technology, 2009.

[14] G. Bugár, M. Vološin, T. Maksymyuk et al., "Techno-economic framework for dynamic operator selection in a multitier heterogeneous network," Ad Hoc Networks, vol. 97, p. 102007, 2020.

[15] X. Zhou and H. Zheng, TRUST: A General Framework for Truthful Double Spectrum Auction, INFOCOM IEEE, 2012.

[16] Y. N. Shnaiwer, S. A. Zummo, W. Mesbah, and S. A. Ahmadi, "Cost-efficient secondary users grouping for two-tier cognitive radio networks," Physical Communication, vol. 25, no. 1, pp. 1-13, 2017.

[17] M. A. Khan and M. M. Jamali, "Carrot and stick model for dynamic secondary radio spectrum trade with QoS optimization," Physical Communication, vol. 29, pp. 203-216, 2018.

[18] M. A. Khan and M. M. Jamali, "Quality of Service optimization-based dynamic secondary spectrum access model using Genetic Algorithms," Transactions on Emerging Telecommunications Technologies, vol. 29, no. 8, 2017.

[19] I. Anjum, M. A. Razzaque, M. M. Hassan, A. Alelaiwi, and S. M. Mizanur Rahman, "Quality-of-service-aware weightedfair medium access control protocol for coexisting cognitive radio networks," EURASIP Journal on Wireless Communications and Networking, vol. 2016, no. 1, 2016.

[20] Z. Tabakovic and M. Grgic, "Cognitive radio frequency assignment with interference weighting and categorization," EURASIP Journal on Wireless Communications and Networking, vol. 2016, no. 1, 2016.

[21] L. Zhai, H. Wang, and C. Gao, "A Spectrum Access Based on Quality of Service (QoS) in Cognitive Radio Networks," PLoS One, vol. 11, no. 5, 2016.

[22] A. Elarfaoui and N. Elalami, "Optimization of QoS parameters in cognitive radio using combination of two crossover methods in genetic algorithm," International Journal of Communications, Network and System Sciences, vol. 16, no. 11, pp. 478-483, 2013. 
[23] M. Pan, J. Sun, and Y. Fang, "Purging the back-room dealing: secure spectrum auction leveraging paillier cryptosystem," IEEE Journal on Selected Areas in Communications, vol. 29, no. 4, pp. 866-876, 2011.

[24] Z. Ji and K. Liu, "Multi-stage pricing game for collusionresistant dynamic spectrum allocation," IEEE Journal on Selected Areas in Communications, vol. 26, no. 1, pp. 182191, 2008.

[25] S. Sengupta and M. Chatterjee, "Designing auction mechanisms for dynamic spectrum access," Mobile Networks and Applications, vol. 13, no. 5, pp. 498-515, 2008.

[26] L. Gao, Y. Xu, and X. Wang, "Map: multiauctioneer progressive auction for dynamic spectrum access," IEEE Transactions on Mobile Computing, vol. 10, no. 8, pp. 1144-1161, 2011.

[27] L. Guijarro, V. Pla, J. R. Vidal, and J. Martinez-Bauset, "Entry, competition, and regulation in cognitive radio scenarios: a simple game theory model," Mathematical Problems in Engineering, vol. 2012, 13 pages, 2012.

[28] S. Gandhi, C. Buragohain, L. Cao, H. Zheng, and S. Suri, "Towards real-time dynamic spectrum auctions," The International Journal of Computer and Telecommunications Networking, vol. 52, no. 4, pp. 879-897, 2008.

[29] E. Cronin, A. R. Kurc, B. Filstrup, and S. Jamin, "An efficient synchronization mechanism for mirrored game architectures," Multi- media Tools and Applications, vol. 23, no. 1, pp. 7-30, 2004.

[30] D. Randall, P. Goel, and R. Abujamra, "Blockchain applications and use cases in health information technology," Journal of Health\& Medical Informatics, vol. 8, no. 3, pp. 8-11, 2017.

[31] S. Huckle, R. Bhattacharya, M. White, and N. Beloff, "Internet of things, blockchain and shared economy applications," Procedia Computer Science, vol. 98, pp. 461-466, 2016.

[32] N. Kshetri, "Can blockchain strengthen the internet of things?," IT Professional, vol. 19, no. 4, pp. 68-72, 2017.

[33] M. Pilkington, Blockchain Technology: Principles and Applications, Research handbook on digital transformations Edward Elgar Publishing, 2016.

[34] M. B. Weiss, K. Werbach, D. C. Sicker, and C. E. C. Bastidas, "On the application of blockchains to spectrum management," IEEE Transactions on Cognitive Communications and Networking, vol. 5, no. 2, pp. 193-205, 2019.

[35] J. Qiu, D. Grace, G. Ding, J. Yao, and Q. Wu, "Blockchainbased secure spectrum trading for unmanned-aerial-vehicleassisted cellular networks: an operator's perspective," IEEE Internet of Things Journal, vol. 7, no. 1, pp. 451-466, 2019.

[36] T. Maksymyuk, J. Gazda, L. Han, and M. Jo, "BlockchainBased Intelligent Network Management for 5G and Beyond," in 2019 3rd International Conference on Advanced Information and Communications Technologies (AICT), pp. 36-39, 2019.

[37] S. Zheng, T. Han, Y. Jiang, and X. Ge, "Smart contract-based spectrum sharing transactions for multi-operators wireless communication networks," IEEE Access, vol. 8, pp. 8854788557, 2020.

[38] Z. Zhou, X. Chen, Y. Zhang, and S. Mumtaz, "Blockchainempowered secure spectrum sharing for $5 \mathrm{~g}$ heterogeneous networks," IEEE Network, vol. 34, no. 1, pp. 24-31, 2020.

[39] U. U. Khan, N. Dilshad, M. H. Rehmani, and T. Umer, "Fairness in cognitive radio networks: models, measurement methods, applications, and future research directions," Journal of Network and Computer Applications, vol. 73, pp. 12-26, 2016.
[40] D. Dranove, C. Garthwaite, and C. Ody, A Floor-And-Trade Proposal to Improve the Delivery of Charity-Care services by U.S. Nonprofit Hospitals, Hamilton Project, Northwestern Univ, 2015.

[41] C. Wang and P. Guo, "Behavioral models for first-price sealedbid auctions with the one-shot decision theory," European Journal of Operational Research, vol. 261, no. 3, pp. 9941000, 2017. 